\title{
Expression of a Novel Protocadherin, OL-Protocadherin, in a Subset of Functional Systems of the Developing Mouse Brain
}

\author{
Shinji Hirano, Qiong Yan, and Shintaro T. Suzuki \\ The Doheny Eye Institute and the Departments of Ophthalmology and Microbiology, University of Southern California \\ School of Medicine, Los Angeles, California 90033
}

\begin{abstract}
We cloned a novel protocadherin cDNA, which we named OL-protocadherin (OL-pc), from mouse brain cDNA libraries. Its cytoplasmic region showed no similarities to other protocadherins, indicating that it belongs to a novel subfamily of protocadherins. Experiments using transfectants showed that OL-pc is a homophilic cell-cell adhesion molecule. The molecular mass of OL-pc was $140 \mathrm{kDa}$ in the brain. Expression of OL-pc mRNA was specific to the nervous system, changing over time from the embryonic stage to the adult stage. The OL-pc expression seemed to be restricted to a subset of functionally related brain nuclei and regions such as the nuclei in the main olfactory system, the limbic system, and the olivocortical projection. There were at least two distinct patterns of distribu-
\end{abstract}

Cell-cell adhesion is a basic process in the morphogenesis of multicellular organisms. It usually includes two aspects that often occur simultaneously: mechanical adhesion to form the tissue structure and recognition of surrounding cells via signal transduction.

Classical cadherins are the major cell-cell adhesion molecules in multicellular organisms (Takeichi, 1988, 1995). They play critical roles in animal morphogenesis through fundamental processes, such as the establishment of cell polarity, cell-sorting, cell proliferation, neurite extension, and fasciculation of axons. Moreover, recent studies have suggested that cadherins are involved in the formation of functional subdivisions and neural networks in

\footnotetext{
Received Aug. 11, 1998; revised Nov. 5, 1998; accepted Nov. 6, 1998.

This work was supported in part by National Institutes of Health Grants NS32456 and EY03040, the Hoover Foundation, ICOS Corporation, Research to Prevent Blindness Inc., Grants-in-Aid of the Ministry of Education of Japan, and the Sumitomo Foundation. S.H. was the recipient of a long-term fellowship from Toyobo Biotechnology Foundation in 1995 and from the Human Frontier Science Program in 1996 and 1997. We thank Masatoshi Takeichi for his generous help, including supplying us with materials and allowing us to conduct some of our experiments in his laboratory. We thank Dr. Tadashi Uemura, Dr. Akira Nagafuchi, Sachihiro C. Suzuki, and Taro Tanaka for their technical suggestions, Dr. Christhoph Redies for his thoughtful comments on this manuscript, Dr. Sachiko Murase for providing the C4-11 transfectant, and Drs. Shyuichi Obata and C.-M. Chuong for providing the necessary equipment. We also thank Drs. Xiaopeng Wang, Hidenobu Tanihara, Sonoko Furuya, Stan M. Hollenberg, Charles Haun, members of the Department of Perinatology (Institute for Developmental Research) for their generous help, Dr. Suzanne Horvash and Linn Williams for performing the peptide synthesis, and Susan Clarke for editorial assistance. We thank Dr. Eiko Aoki and Ikuko Iwamoto for their technical assistance.

Correspondence should be addressed to Dr. Shintaro T. Suzuki, Institute for Developmental Research, Aichi Human Service Center, Kamiya-cho 713-8, Kasugai City, Aichi 480-0392, Japan.

Dr. Hirano's and Dr. Suzuki's present address: Institute for Developmental Research, Aichi Human Service Center, Kamiya-cho 713-8, Kasugai City, Aichi 480-0392, Japan

Dr. Yan's present address: Department of Ophthalmology, Xi'an Fourth Hospital, 13 Jiefang Road, Xi'an, Shaanxi, 710004, People's Republic of China

Copyright (C) 1999 Society for Neuroscience $\quad 0270-6474 / 99 / 190995-11 \$ 05.00 / 0$
}

tion for the OL-pc protein. First, it was localized in particular brain nuclei or compartments, such as the stripes of the developing cerebellum. Second, it was found at the synapse in regions such as the glomeruli of the olfactory bulb. In addition, the OL-pc protein seemed not to be detected or was detected only weakly in some regions, such as hippocampus in which the mRNA was expressed at high levels. These results indicate that the expression of OL-pc is developmentally regulated in a subset of the functional systems and that it may be involved in the formation of the neural network by segregation of the brain nuclei and mediation of the axonal connections.

Key words: cadherin; protocadherin; cell adhesion molecule; cell-cell interaction; neural network; olfactory system

the CNS (Redies, 1995; Takeichi, 1995; Redies and Takeichi, 1996). Cadherins are localized at the adherens junctions. For example, in epithelial cell layers, it forms the zonula adherens (Takeichi, 1988), and in the nervous system, N-cadherin is also localized at the synapse (Yamagata et al., 1995; Fannon and Colman, 1996; Uchida et al., 1996).

Recently, a variety of molecules have been identified as members of the cadherin superfamily, including desmosomal cadherins, LI-cadherin, and the fat tumor suppressor gene product in Drosophila (for review, see Suzuki, 1996a,b). The molecules of the cadherin superfamily have versatile functions; some are involved in mechanical adhesion, whereas others are involved in signal transduction, growth control, etc.

Protocadherins are collective members of the cadherin superfamily that were originally identified by use of the PCR method (Sano et al., 1993). These molecules contain five or six cadherin repeats in their extracellular domains, but their cytoplasmic regions have no similarity to those of classical cadherins. Moreover, recent studies have shown that protocadherins comprise subgroups, such as the protocadherin 2 (pc2) and protocadherin 3 (pc3) subgroups, which are made up of closely related members (Sago et al., 1995; Kohmura et al., 1998; Obata et al., 1998, Yamamoto et al., 1998). Protocadherins appear to be widely expressed in a variety of tissue types, although many are highly specific to nervous tissue (Sano et al., 1993; Sago et al., 1995; Matsuyoshi and Imamura, 1997; Obata et al., 1998; Yoshida et al., 1998). To our knowledge, no close analysis has been done yet of the expression pattern of protocadherins in the brain. Two novel protocadherins recently cloned in Xenopus, NF-protocadherin and paraxial protocadherin, were shown to be involved in cell adhesion of ectoderm and mesoderm, respectively (Bradley et al., 1998, Yamamoto et al., 1998); however, the functions and roles of other protocadherins remain unknown. One subfamily of pro- 


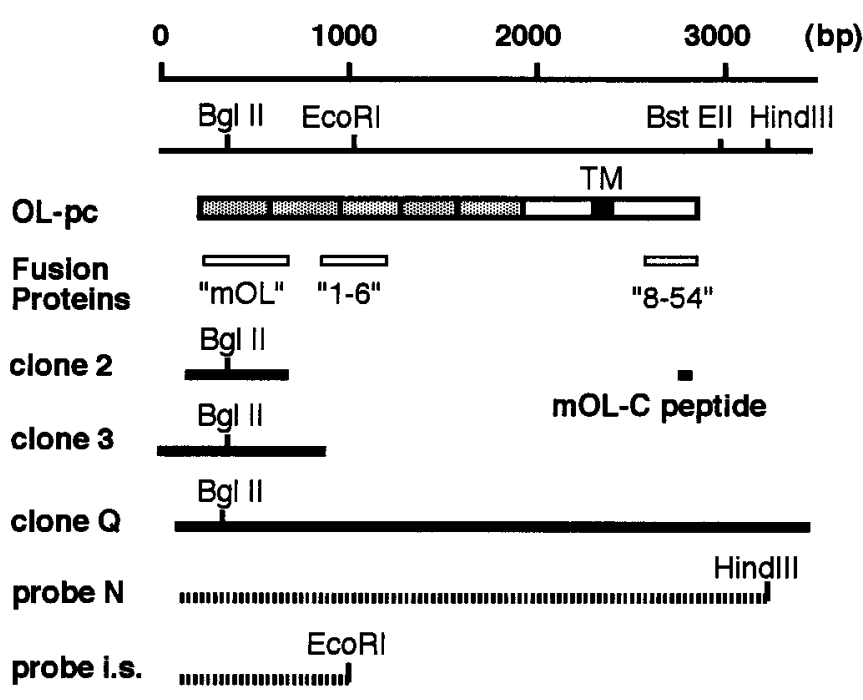

Figure 1. Relationship of cDNA clones, fusion proteins, a peptide, probes, and the restriction map. A model of the deduced OL-pc molecule is also indicated. Probe $N$ was used for Northern blot analysis, and probe i.s. was used for in situ hybridization. TM, Transmembrane domain; $b p$, base pair.

tocadherins, Fyn-binding cadherin-related neuronal receptor (Cnr), was recently shown to be localized at the synaptic complex (Kohmura et al., 1998).

In the present study, we cloned a novel protocadherin [OLprotocadherin (OL-pc)] cDNA from mouse brain libraries. We characterized OL-pc and examined its expression pattern in the developing mouse brain. This is the first comprehensive description of the expression of a protocadherin in the CNS. Herein, we will describe our results and discuss the possible functions of this protocadherin in the formation of the neural network.

\section{MATERIALS AND METHODS}

Animals. Wistar and Donryu rats were used for immunization of fusion proteins. ICR and DDY mice were used for in situ hybridization. The day the cervical plug was observed was regarded as embryonic day 0 (E0). The day the animals were born was regarded as postnatal day 0 (P0).

Screening of cDNA libraries. We screened the mouse cDNA libraries according to the standard method (Huynh et al., 1985). All hybridization was performed at $42^{\circ} \mathrm{C}$ with a hybridization buffer containing $40 \%$ formamide, $5 \times$ SSC, $0.1 \%$ SDS, $2.5 \times$ Denhardt's reagent, and $25 \mathrm{~mm}$ phosphate buffer. The probe was prepared with a random primer labeling kit (Boehringer Mannheim, Indianapolis, IN). For OL-pc, a 580 bp fragment from the $5^{\prime}$ region of human pc2 cDNA was used as a screening probe (Sano et al., 1993). Two cDNA fragments of OL-pc (Fig. 1, clones $2,3)$ were isolated from $\sim 2.5 \times 10^{5} \lambda$ gt10 phage recombinants of a random-primed E14 mouse whole-brain cDNA library. Using clone 2 for further screening, we isolated one full-length cDNA (clone Q) from $3.5 \times 10^{5}$ phages of an oligo dT-primed E14 mouse whole-brain $\lambda$ gt10 library (Miyatani et al., 1989).

Transfection of $L$ cell and Neuro2A cell line with $O L-p c$. Because clone $\mathrm{Q}$ has one base deletion at the position $113 \mathrm{bp}$ from the $5^{\prime}$ end, we replaced the $5^{\prime}$ regions of clone Q with clone 2 at the $B g l$ II site. This recombinant was then subcloned into the pRcRSV mammalian expression vector (Invitrogen, San Diego, CA). After purification of the DNA with a plasmid purification kit (Qiagen, Valencia, CA), L cells and Neuro2A cells were transfected with the DNA by the calcium phosphate transfection method (Cellphect kit; Amersham Pharmacia Biotech, Uppsala, Sweden). After selection with Geneticin (G418; Gibco, Rockville, $\mathrm{MD}$ ), colonies were randomly picked up and subjected to Western blotting and immunocytochemical analysis. We established several clones for each cell line. The properties of these clones were basically the same, although the amount of OL-pc they expressed differed.

Cell aggregation assay. The cell aggregation assay was performed basically according to the method described by Takeichi (1977). How- ever, we used $0.05 \%$ trypsin in the presence of $10 \mathrm{~mm} \mathrm{Ca}^{2+}$ (TC treatment) for dissociation of cells, because protocadherins seemed to be more sensitive than classical cadherins to trypsin. The incubation time was increased to 4-6 hr in total to recover OL-pc after the trypsin digestion. The extent of cell aggregation was represented by the index $\left(N_{0}-N_{\mathrm{t}}\right) / N_{0}$, where $N_{\mathrm{t}}$ is the total particle number after the incubation time $t$ (minutes) and $N_{0}$ is the total particle number at the initiation of incubation (Nagafuchi and Takeichi, 1988).

Production of antibodies. We made fusion protein constructs composed of OL-pc and glutathione $S$-transferase (GST) (Amersham Pharmacia Biotech) or maltose-binding protein (MBP) (New England Biolabs, Beverly, MA). The "mOL" fusion proteins with GST or MBP contained the 16-157 amino acid (aa) residue; the " $1-6$ " fusion protein with GST covers the 227-336 aa residue; and the " $8-54$ " fusion protein with GST contains the 799-896 aa residue of OL-pc (Fig. 1). With the help of Dr.Suzanne Horvash (California Institute of Technology, Pasadena, CA) and Ms. Linn Williams (Kenneth J. Norris Cancer Center/University of Southern California, Los Angeles, CA), we also made an oligopeptide, GSILSNEVRLKGKK (mOL-C), which corresponds to the area 871884 aa residue of OL-pc.

We immunized rats and rabbits three to six times, with a $14 \mathrm{~d}$ interval between each immunization. All of the antisera against these fusion proteins recognized a $115 \mathrm{kDa}$ band by Western blotting of the OL-pc transfectants. Among these, only the 8-54 serum could be used for immunocytochemical analysis. We asked an independent source (Cocalico Biologicals, Reamstown, PA) to perform immunization of a rabbit with the peptide. The rat and rabbit antisera to the peptide mOL-C could also be used for cell staining.

To produce monoclonal antibodies, the spleens were removed from immunized rats, and the splenocytes were fused with P3U1 myeloma according to the conventional method (Kohler and Milstein, 1975). Screening of the hybridoma was performed with small strips of Western blot of L cell transfectants. Monoclonal antibodies (mAbs) 2B4 and 2G8 recognized the $\mathrm{mOL}$ fusion protein, and $\mathrm{mAbs} 1 \mathrm{G} 12,2 \mathrm{H} 7$, and $2 \mathrm{H} 8$ recognized the 8-54 fusion protein. These antibodies could be used for Western blot analysis, but only $2 \mathrm{H} 7,2 \mathrm{H} 8$, and $1 \mathrm{G} 12$ could be used for immunocytochemical testing. The results with $2 \mathrm{~B} 4$ and $2 \mathrm{G} 8$ were basically the same, and the results with $2 \mathrm{H} 7,2 \mathrm{H} 8$, and $1 \mathrm{G} 12$ were the same among this group of antibodies, although the affinity was different.

Immunohistochemical analysis. Immunohistochemical analysis for transfectants was performed as described previously, with the exception that $-20^{\circ} \mathrm{C}$ methanol or acetone was used for fixation and permeabilization (Hirano et al., 1992), because paraformaldehyde fixation reduced the staining signal with $1 \mathrm{G} 12,2 \mathrm{H} 7$, and $2 \mathrm{H} 8 \mathrm{mAbs}$. For tissue sections, unfixed samples were embedded directly in OCT compound (Sakura, Torrance, CA). After air drying, the sections were fixed with $4 \%$ paraformaldehyde for a few minutes to remove the OCT and then washed with $50 \mathrm{~mm}$ Tris-buffered saline containing $1 \mathrm{~mm}$ calcium chloride (TBS-Ca), pH 7.4. The sections were fixed and permeabilized with $-20^{\circ} \mathrm{C}$ acetone for $20 \mathrm{~min}$ and then air dried. After blocking with $5 \%$ skim milk in TBS-Ca, the sections were incubated with antibodies. Staining signals were very weak, partly because the affinity of the antibodies may not have been strong enough and partly because there may not have been sufficient antigen to detect. With the mAbs $2 \mathrm{H} 7,2 \mathrm{H} 8$, and $1 \mathrm{G} 12$, we used $\mathrm{Cy} 3$-conjugated streptavidin or Cy3-conjugated secondary antibody (Jackson ImmunoResearch, West Grove, PA). For wholemount staining, we followed the procedure described by Fujimori et al. (1990), but we fixed the samples with $-20^{\circ} \mathrm{C}$ acetone and used TBS-Cabased buffer for washing and incubation.

Fluorescent cytochemistry of mixed cultures. Vital cell staining with $5(-6)$ carboxylfluorescein diacetate succinimidyl ester (CFSE) was done according to Hirano et al. (1987). For staining of OL-pc, the procedure was essentially the same as that used for tissue sections after cutting. For the double staining of different cadherins, we used mAbs $2 \mathrm{H} 7$ or $2 \mathrm{H} 8$ for OL-pc and rabbit polyclonal antisera for pc3 (Sago et al., 1995) and $\alpha$ catenin (Sigma, St. Louis, MO). We used antibody to $\alpha$ catenin to see the localization of N-cadherin, because mouse N-cadherin antibody was not available. We used Cy3-conjugated anti-rabbit antibody (Jackson ImmunoResearch) and biotinylated anti-rat antibody and fluoresceinconjugated streptavidin (Amersham Pharmacia Biotech) for detection. Double-stained samples were examined and photographed by an Olympus fluorescence microscope using dual filter WIB for both Cy3 and fluorescein (Olympus Optical, Tokyo, Japan). Fluorescein fluorescence remained green on photographs, whereas the red color of $\mathrm{Cy} 3$ became 
orange through the microscope and yellow on photographs taken with Ektachrome P1600 film (Eastman Kodak, Rochester, NY).

Western blot analysis. Samples were dissolved in the SDS-PAGE sample buffer at 10 times the volume of the tissue or cells and then separated by SDS-PAGE using 6\% polyacrylamide gels. After electrophoresis, the proteins were transferred onto an Immobilon-P membrane (Millipore, Bedford, MA). The sheets were incubated with 5\% skim milk in TBSCa. After incubation with the primary antibodies, an alkaline phosphatase-conjugated antibody (Promega, Madison, WI) was applied.

Northern blot analysis. Total RNA was isolated by the conventional method of Sambrook et al. (1989). Twenty (see Fig. 7A) or 40 (see Fig. $7 B) \mu \mathrm{g}$ of total RNA was loaded onto a $1 \%$ denatured gel, and RNA was then transferred to a Hybond $\mathrm{N}^{+}$membrane (Amersham Pharmacia Biotech). The probe for OL-pc was the HindIII fragment of clone Q (Fig. 1). Hybridization was performed under the same conditions used for library screening, except for a final $30 \mathrm{~min}$ washing with $0.2 \times \mathrm{SSC}$ at $65^{\circ} \mathrm{C}$.

In situ hybridization. Samples were fixed overnight with $4 \%$ paraformaldehyde. For the neonatal and adult mice, perfusion was done with $4 \%$ paraformaldehyde beforehand. Tissue sections of $15 \mu \mathrm{m}$ thickness were cut with a cryostat, and slices of $300 \mu \mathrm{m}$ thickness were prepared with a vibratome.

Whole-mount in situ hybridization was performed according to the method described by Wilkinson (1992). The 900 bp EcoRI region of OL-pc was selected as the probe (Fig. 1). RNA probes were prepared with the Genus kit (Boehringer Mannheim), and sense strands were used as a negative control. In situ hybridization of tissue sections was performed according to previously described methods (Suzuki et al., 1997).

For identification of brain nuclei, we consulted atlases, such as those of Franklin and Paxinos (1997) and Schambra et al. (1992). Terminology was basically that used in the atlas of Franklin and Paxinos (1997) and Paxinos' (1994) book on the rat nervous system.

\section{RESULTS}

\section{Molecular cloning of OL-pc in the mouse brain}

To clone mouse protocadherins, we screened mouse brain cDNA libraries using the cDNA fragment of human pc2 as a probe. We isolated clones corresponding to a novel protocadherin over the full length of their coding region (Figs. 1, 2). The GenBank accession number is U88549. We named this novel protocadherin OL-pc, because it was characteristically expressed in the olfactory and limbic systems of the brain (see below). OL-pc was found to be 896 aa in length (Fig. 2). The putative initiation codon did not conform to the consensus sequence of Kozak (1984), but the first 13 aa were hydrophobic, which seems to be a signal sequence for membrane proteins. The extracellular domain 2 (EC2) had a 19 aa insertion, which has not been reported in other protocadherins. This domain showed a $44 \%$ aa identity with human pc2 throughout the extracellular domain (number of identical aa per number of total aa of the pc2 extracellular domain). However, its cytoplasmic region showed no significant similarity with any other cadherins so far identified, indicating that OL-pc belongs to a novel subfamily of protocadherins.

\section{Introduction of OL-pc into mouse cell lines}

To address the basic features of OL-pc, we expressed OL-pc in mouse L and Neuro2A cell lines. Western blot analysis of these transfectants detected a smear band at the position of $\sim 115 \mathrm{kDa}$, which seemed to be composed of a few bands close to one another (Fig. $3 A$ ). In contrast to what is seen with classical cadherins, these bands became much weaker after TC treatment (data not shown).

The morphology of the L cell transfectants (OL) did not change dramatically, unlike the case for transfection with classical cadherins, which makes spindle-shaped L cells into a more epithelial type. However, the subcellular localization of OL-pc was reminiscent of that of the classical cadherin in transfectants (Fig. 4). OL-pc protein was concentrated only at the cell-cell adhesion

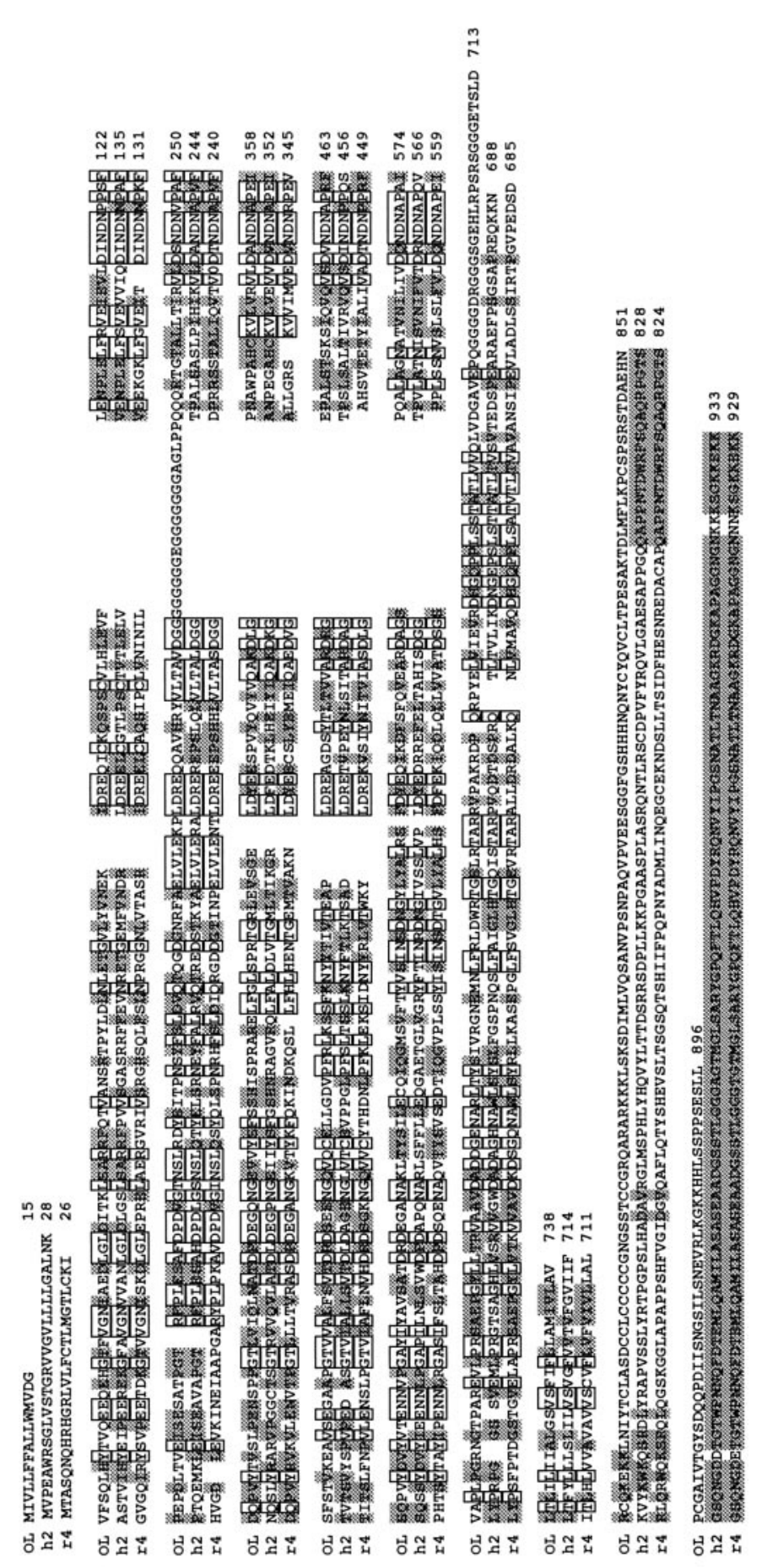

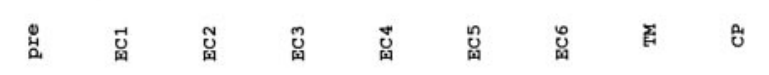

Figure 2. Amino acid sequence comparison of mouse OL-pc, human $\mathrm{pc} 2$, and rat pc4. Amino acid residues are boxed if completely conserved and shadowed if more than two amino acids are identical among the three protocadherins. Note that the members of the pc2 family (pc2 and pc4) have a conserved sequence at the $\mathrm{C}$-terminal region. $O L$, Mouse $\mathrm{OL}-\mathrm{pc}$; $h 2$, human pc2; r4, rat pc4; pre, precursor region; $E C$, extracellular domain; TM, transmembrane domain; $C P$ cytoplasmic domain. Numbers indicate the position of amino acid residues. 


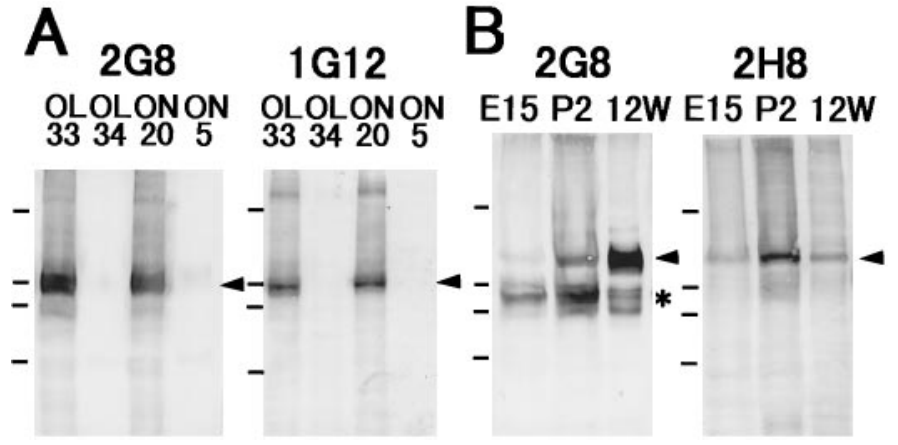

Figure 3. Western blot analysis of OL-pc. $A$, OL-pc is detected in L cell transfectants $(O L)$ and Neuro2A transfectants $(O N)$ with mAbs 2G8 and 1G12. OL34 and ON5 are OL-pc-negative cells, with only G418 resistance. $B, \mathrm{OL}-\mathrm{pc}$ is detected in the brain samples with $\mathrm{mAbs} 2 \mathrm{G} 8$ and $2 \mathrm{H} 8$. Samples were prepared from E15 and P2 whole brains and from 12-weekold Hip $(12 W)$. Note that the $140 \mathrm{kDa}$ band is single and that the staining with $\mathrm{mAb} 2 \mathrm{H} 8$ is much weaker than that with $\mathrm{mAb} 2 \mathrm{G} 8$ in the 12-weekold Hip. Arrowheads indicate the positions of OL-pc. Asterisk indicates smaller bands of $\sim 100 \mathrm{kDa}$. Bars show the positions of molecular weight markers for 200, 116, 97, and $66 \mathrm{kDa}$.
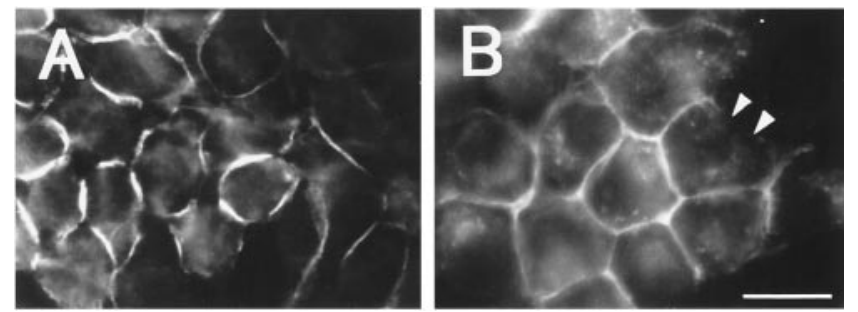

Figure 4. Localization of OL-pc in transfected cells. $A$, L cell transfectants (OL33) were stained with mAb1G12. $B$, Neuro2A transfectants (ON20) were stained with anti-8-54 serum. Note that only cell-cell junctions are stained and that the free edge lacks the staining (arrowheads). Scale bar, $50 \mu \mathrm{m}$.

site in these transfectants and was absent from the free edges of cells (Fig. 4B).

Next, we performed the cell aggregation assay, using the transfectants (Fig. 5). Because OL-pc was digested by TC treatment, the OL transfectant could not aggregate in the short-term incubation. It showed some differences from parental L cells in the long-term culture, although its aggregation activity was lower than that of cells transfected with classical cadherin (Fig. $5 A-C$, $F)$. The final size of the aggregates was smaller than that of classical cadherin transfectants (Fig. $5 A, C$ ). Unlike the case with classical cadherins, the individual cells in the aggregates remained round (Fig. 5D,E). These observations suggest that newly synthesized OL-pc mediated weak aggregation and may have not linked firmly with cytoskeletal elements in the transfectants.

To examine the binding specificities of the OL-pc molecule, we mixed OL-pc transfectants with transfectants of various protocadherins and classical cadherins and examined whether OLprotocadherin is concentrated at the cell-cell junction (Fig. 6). It is known that the phenomena of adhesion activity, localization at the cell-cell junction, and binding of catenins are inseparable in the case of classical cadherins; cadherins are concentrated at the cell-cell junction and bind catenins only if they are active in adhesion (Takeichi, 1991). Because OL-pc in transfectants had adhesion activity and was localized exclusively at the cell-cell adhesion site, we postulated that the same assumption could be
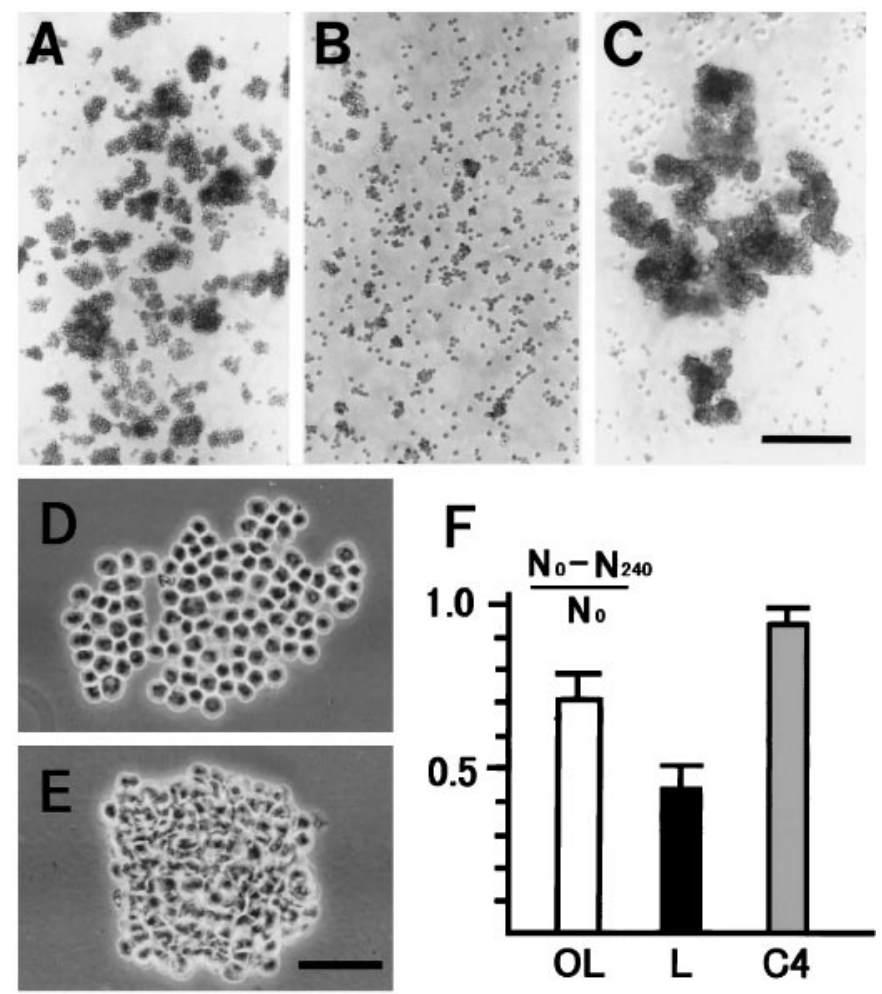

Figure 5. Aggregation of OL-pc transfectant, L cell, and classical cadherin-4 (R-cadherin) transfectant. After dissociation of cells with trypsin in the presence of calcium ions, cells were incubated with gyratory shaking for $4 \mathrm{hr}$. $A$, OL33 (OL-pc) transfectant. $B$, G418-resistant L cell. $C, \mathrm{C} 4$ cadherin transfectant. Note that the size of aggregates of OL33 is smaller than that of aggregates of the $\mathrm{C} 4$ transfectant. $D$, Higher magnification of an OL33 aggregate mounted between a coverslip and a slide glass. Individual cells retain a rounded morphology. $E$, Higher magnification of a $C 4$ transfectant aggregate mounted similarly as in $D$. Note that individual cells are compactly packed. $F$, Qualitative analysis of adhesion activities of the transfectants. A higher value represents a higher degree of aggregation. Scale bars: (in $C$ ) $A-C, 250 \mu \mathrm{m}$; (in $E$ ) $D, E, 20 \mu \mathrm{m}$.

applied to the localization and adhesion activity. The results showed that OL-pc did not accumulate between the contact sites of transfectants of OL-pc and pc2 or pc3 (Fig. 6A-D, G), suggesting that $\mathrm{OL}-\mathrm{pc}$ does not interact with other protocadherins. A similar result was obtained using classical cadherins [mouse $\mathrm{N}$-cadherin (Fig. $6 H$ ), human $\mathrm{C} 4$ cadherin, and rat cadherin-8; data not shown]. Thus, we concluded that the interaction of OL-pc is specific and that OL-pc acts in a homophilic manner.

\section{Expression pattern of OL-pc}

Northern blot analysis showed that the expression of OL-pc was seen from the embryonic stage to the adult stage (Fig. $7 A$ ). In the embryonic and postnatal brains, the $8.0 \mathrm{~kb}$ major band could be detected, along with a smear tail (or bands), whereas in the adult brain, the higher band was a $8.4 \mathrm{~kb}$ band, and the smear bands ranging from 3.7 to $5.7 \mathrm{~kb}$ were dominant over the $8.4 \mathrm{~kb}$ band. Its expression was restricted to the nervous system in the adult (Fig. $7 B$ ). Thus, the expression of OL-pc was regulated spatially and temporally during development.

We performed in situ hybridization to address the question of which parts of the brain expressed OL-pc. At E15, its expression could be seen in various parts of the brain, although it was restricted to certain areas (Fig. $8 A-C$ ). Strong expression could be seen at the epithalamus (Epi) and in a pair of strips on the 

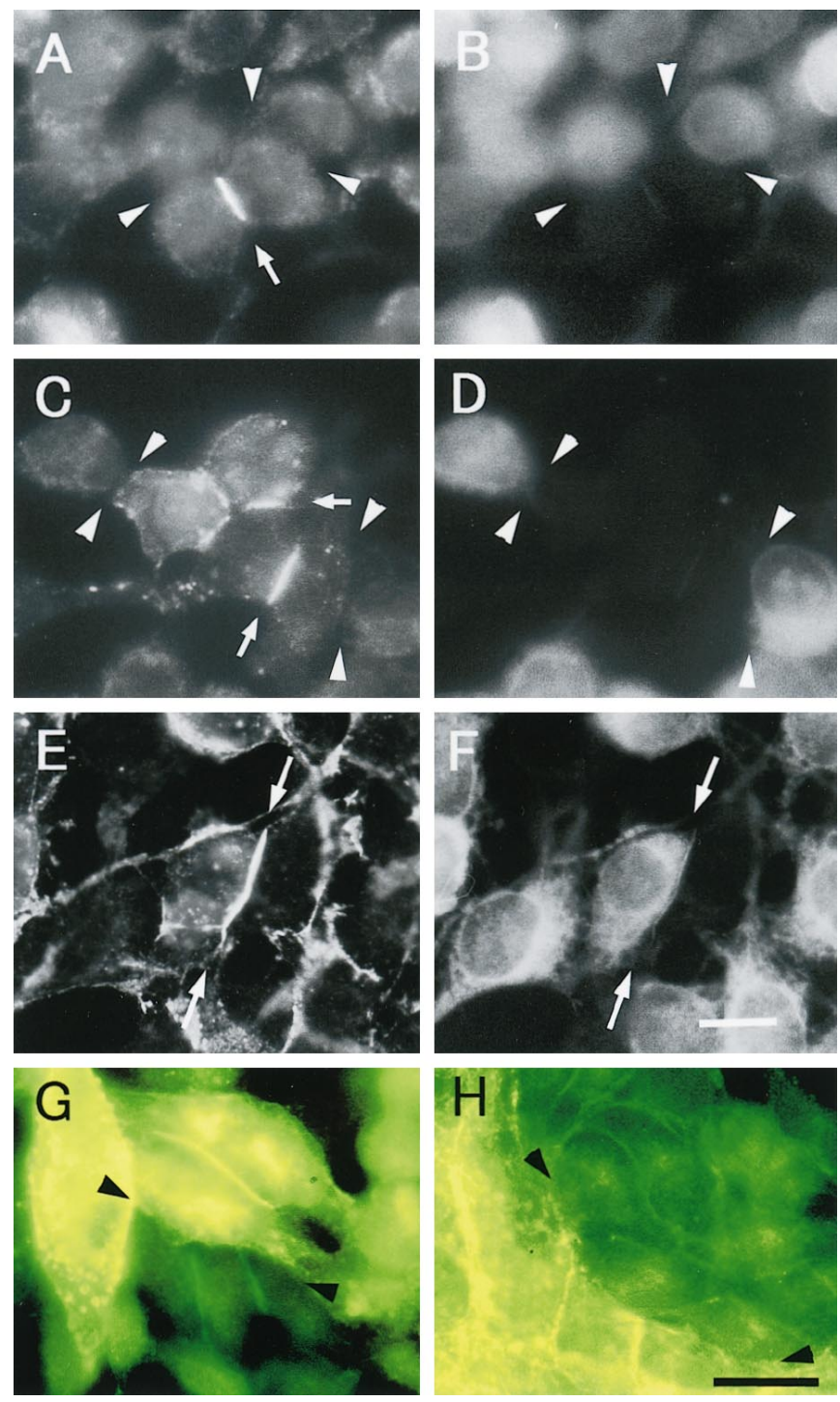

Figure 6. Specificities of OL-pc interaction. $A-F$, One of two transfectants was labeled with CFSE and cocultured to examine OL-pc protein localization at the heterotypic contact site. $A, B$, Mixed culture of OL-pc transfectants and pc2 transfectants. $C, D$, Similar culture of OL-pc transfectants and pc3 transfectants. $E, F$, Positive control culture of OL-pc transfectants and CFSE-labeled OL-pc transfectants. OL-pc was stained $(A, C, E)$, and pc2, pc3, and OL-pc transfectants labeled with CFSE were visualized $(B, D, F) . G, H$, Double staining of two cadherin transfectants in mixed culture. Green represents localization of OL-pc, and yellow represents rat pc3 or mouse cadherin-binding protein $\alpha$ catenin. $G$, Mixed culture of OL-pc transfectants and rat pc3 transfectants. $H$, Mixed culture of OL-pc transfectants and mouse N-cadherin transfectants. Arrowheads indicate the heterotypic contact sites. Arrows indicate the OL-pc signal at the homotypic contact sites of OL-pc $(A, C, E, F)$. Scale bars, $20 \mu \mathrm{m}$.

cerebellar primordium (Fig. $8 A$ ). Moderate expression was noted in areas such as the superior colliculus (SC) and the frontal cortex, including the cingulate cortex $(\mathrm{Cg})$, the orbitofrontal cortex (OC), and the agranular insular cortex (AI) in which the boundaries were sharp (Fig. $8 \mathrm{~A}, \mathrm{C}$ ). In addition, many patchy regions, including the olfactory tubercle $(\mathrm{Tu})$, expressed OL-pc on the ventral side of the brain (Fig. $8 B$ ). At E15, OL-pc was also expressed in the nuclei inside the brain that appeared to correspond to the positive areas at P2 (see below, Table 1). At E18, expression seemed to be restricted to certain regions, although
A
E16 P1 8W

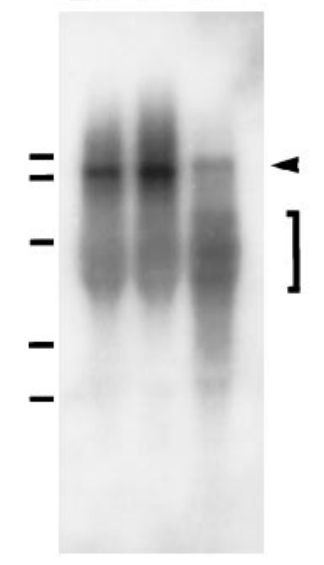

B

\section{$\mathrm{Br}$ Ln Hr Lv Kd Ms}

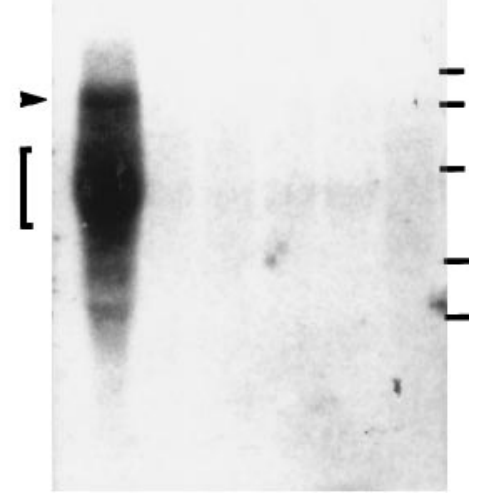

Figure 7. Northern blot analyses of OL-pc. A, Northern blot analysis of brains of different stages. The OL-pc transcripts consisted of a higher band (arrowheads) and lower smear bands ranging from 3.7 to $5.7 \mathrm{~kb}$ (brackets). Note that the relative strength of the bands changes during development. $B$, Northern blot analysis of OL-pc in various adult mouse tissues. The autoradiograph of $B$ was overexposed to see the faint signal of expression. The positions of the molecular markers are 9.5, 7.5, 4.4, 2.4, and $1.3 \mathrm{~kb}$. $B r$, Whole brain; $L n$, lung; $H r$, heart; $L v$, liver; $K d$, kidney; $M s$, muscle.

OL-pc was still expressed in many regions (Fig. $8 D, E$ ). The ventral side of the pons and medulla produced a signal only in some nuclei, such as the principal sensory trigeminal nucleus (Pr5) and medial accessory olive (MAO) region of the inferior olive (Fig. 8E). The cerebellum (Cer) showed several stripespatches, but their intensity appeared to be lower than those seen on E15 (Fig. $8 A, D$ ).

Next, we examined the expression pattern in the postnatal brain in detail (Fig. 9). Although most regions of the brain seemed to express OL-pc to some extent, the signal in some parts was apparently stronger than that of others. Strong expression could be seen in the following: at the $\mathrm{Tu}$; in some parts of the amygdala, including the nucleus of the lateral olfactory tract (LOT), the lateral amygdaloid nucleus (La), and the basolateral amygdaloid nucleus (BL); in the thalamic nuclei, including the mediodorsal (MD), ventromedial (VM), and submedius (Sub) thalamic nuclei; and in the MAO (Fig. $9 A-H, J, O, P$ ). Moderate expression could be seen at the mitral cell layer of the olfactory bulb (Mit) (Fig. 9M), Cg, AI, lateral septum (Sep), caudate putamen $(\mathrm{CPu})$, globus pallidus $(\mathrm{GP})$, piriform cortex (Pir), suprachiasmatic nucleus (SCh), hippocampus (Hip), dorsal raphe nucleus (DR), microcellular tegmental nucleus (MiTg), reticulotegmental nucleus of the pons (RtTg), and dorsal tegmental nucleus (DTg). At P5, several bands could be seen on the central lobes of the Cer (Fig. $9 K, L)$. The signal was located in the Purkinje cell layer (Pk) at P2 (Fig. 9N). Other small nuclei of the reticular formation expressed OL-pc, although we could not identify them. The olfactory epithelium (OE) was also positive (Fig. 9I); however, zone I of the OE did not seem to express OL-pc (data not shown) (see Ressler et al., 1993 for zone definition). It is interesting that only the deep layer of the OE, where sensory neurons $(O N)$ are positioned, expressed OL-pc.

In the adult brain, prominent expression could be seen in the following: olfactory bulb in the granule cell layer (Gro), Mit, and glomerular layer (Glo) of the olfactory bulb; in the tenia tecta 

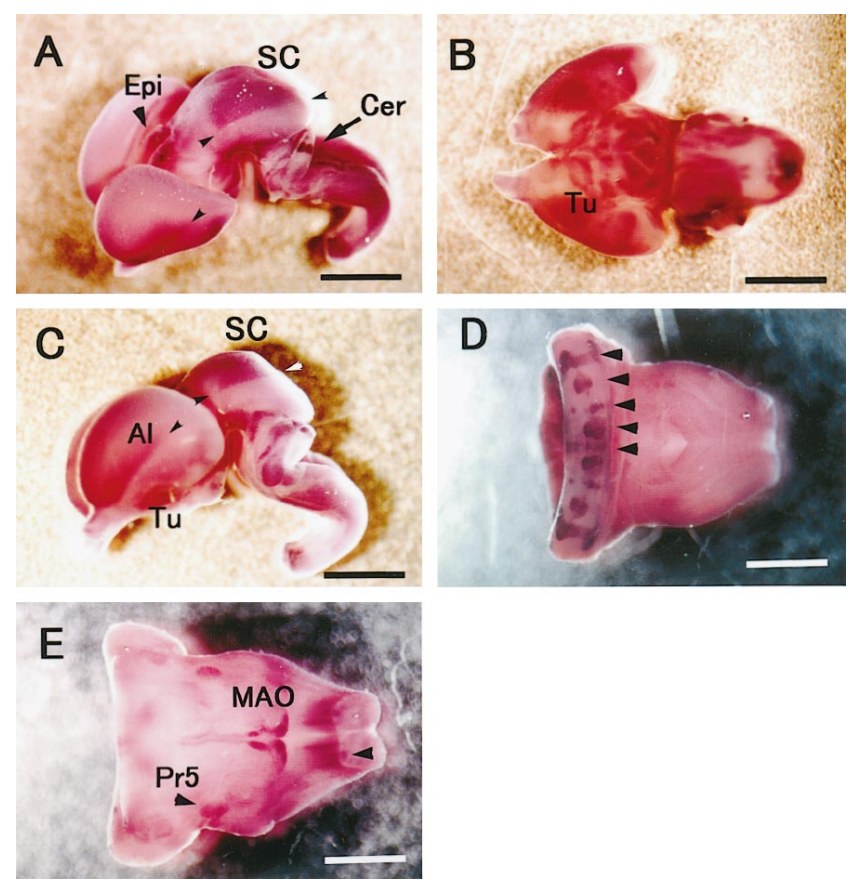

Figure 8. Expression of OL-pc mRNA in the embryonic brain. $A$, Diagonal view of E15 brain. OL-pc is expressed in various regions, including Epi, SC, and a pair of stripes on the Cer, indicated by an arrow. Small arrowheads indicate sharp boundaries of the midbrain and the cortex. $B$, Ventral view of E15 brain. OL-pc is expressed in many patchy regions, including Tu. $C$, Side view of E15 brain. OL-pc is expressed in the AI and SC. The boundary is very sharp (arrowheads). D, Dorsal view of the E18 Cer. Arrowheads indicate stripe-patchy pattern of OL-pc expression. $E$, Ventral view of the E18 brain stem. MAO region of the inferior olive is strongly stained. Arrowheads indicate signal at spinal cord. Abbreviations are listed in Appendix. Scale bars, $1 \mathrm{~mm}$.

(TT); and in the Tu, Pir, LOT, and Hip (Fig. 10). The nuclei of OL-pc-expressing cells in the Pir and Tu were large, suggesting that these cells were neurons (Fig. 10M,N). Many other regions, such as the cortex, entorhinal cortex (Ent), and amygdala, were also positive, but the level of expression was low. Purkinje cells produced only faint signals (Fig. 10H). In the retina, OL-pc was expressed at the ganglion cell layer (GCL) and in a part of the inner nuclear layer (INL) (Fig. 10P).

The expression pattern is summarized in Table 1. Many nuclei that expressed OL-pc mRNA seem to be functionally related. For example, OL-pc was strongly expressed in many nuclei and layers relating to the main olfactory system, including the main olfactory bulb (MOB), TT, Tu, Pir, and LOT (Shipley et al., 1994). The OE, posterolateral cortical amygdaloid nucleus (PLCo), Ent, and DR showed moderate expression. However, OL-pc was not expressed in some nuclei of the olfactory system, such as the anterior olfactory nucleus (AON), the anterior cortical amygdaloid nucleus (ACo), and the accessory olfactory bulb. It was also expressed in some parts of the limbic system, including the OC, the septum, Hip, amygdala, habenular nucleus $(\mathrm{Hb})$, hypothalamus, etc. It is known that the MD is closely related to the frontal cortex and anterior part of basolateral amygdaloid nucleus (BLA) (Price, 1994). A further example of a functional relationship in the OL-pc-expressing regions is that of the cerebellar cortex (Purkinje cells), the cerebellar nuclei, and the MAO (Voogd, 1994).

\begin{tabular}{|c|c|c|c|}
\hline & $\begin{array}{l}\text { Embryonic } \\
(\text { E15, E18) }\end{array}$ & $\begin{array}{l}\text { Postnatal } \\
\text { (P2, P14, P5) }\end{array}$ & $\begin{array}{l}\text { Adult } \\
\text { (8-week-old) }\end{array}$ \\
\hline $\mathrm{OE}$ & & $+\mathrm{p}^{* *}$ & \\
\hline VOE & & $+* *$ & \\
\hline Retina & & + & $+\mathrm{p}$ \\
\hline \multicolumn{4}{|l|}{ Telencephalon } \\
\hline MOB & $+\mathrm{p}$ & + & ++ \\
\hline $\mathrm{AON}$ & & \pm & \pm \\
\hline TT & & & + \\
\hline \multicolumn{4}{|l|}{ Cortex } \\
\hline Neocortex & & $+\mathrm{p}$ & $+\mathrm{p}$ \\
\hline $\mathrm{Cg}$ & + & $+\mathrm{p}$ & $+\mathrm{p}$ \\
\hline AI & + & $+\mathrm{p}$ & $+\mathrm{p}$ \\
\hline Pir & & + & ++ \\
\hline $\mathrm{Tu}$ & ++ & ++ & ++ \\
\hline Ent & & & + \\
\hline Septum & $+\mathrm{p}$ & $+\mathrm{p}$ & \pm \\
\hline $\mathrm{CPu}$ & + & ++ & \pm \\
\hline GP & + & + & \pm \\
\hline AcbSh & & ++ & + \\
\hline Hippocampus & & + & ++ \\
\hline Amygdala & $+\mathrm{p}$ & & \\
\hline $\mathrm{La} / \mathrm{BL}$ & & ++ & + \\
\hline PLCo & & + & ++ \\
\hline PMCo & & + & + \\
\hline LOT & ++ & ++ & ++ \\
\hline $\mathrm{ACo}$ & \pm & \pm & \pm \\
\hline \multicolumn{4}{|l|}{ Diencephalon } \\
\hline Epithalamus & $++\mathrm{p}$ & & \\
\hline $\mathrm{Hb}$ & & + & + \\
\hline Thalamus & $+\mathrm{p}$ & & \\
\hline MD & $++^{*}$ & ++ & \pm \\
\hline $\mathrm{VM}$ & $++^{*}$ & ++ & \pm \\
\hline Hypothalamus & $+\mathrm{p}$ & & \\
\hline $\mathrm{SCh}$ & + & + & \pm \\
\hline Mesencephalon & $+\mathrm{p}$ & & \\
\hline $\mathrm{SC}$ & + & + & + \\
\hline DR & & + & \pm \\
\hline $\mathrm{RtTg}$ & & + & \pm \\
\hline $\mathrm{MiTg}$ & & + & \pm \\
\hline DR & & + & \pm \\
\hline DTg & & + & \pm \\
\hline \multicolumn{4}{|l|}{ Rhombencephalon } \\
\hline Cer & $++\mathrm{p}$ & $+\mathrm{p}$ & $\pm \mathrm{p}$ \\
\hline CerN & & + & \pm \\
\hline Pons and medulla & $+\mathrm{p}$ & & \\
\hline $\operatorname{Pr} 5$ & & + & \pm \\
\hline Pn & & $++\#$ & \pm \\
\hline MAO & ++ & ++ & \pm \\
\hline
\end{tabular}

*, E18; **, P14; \#, P5; ++, strong expression; +, moderate or weak expression; \pm , faint or none. $\mathrm{p}$ indicates that the expression is limited to some areas, layers, and cells. Not all the positive regions are indicated here. At E15 and P2, OL-pc seemed to be expressed, at least faintly, in almost all regions of the brain. Those items left blank are those that were not well examined, in part because identifying these brain nuclei was difficult because of the immaturity of development. Abbreviations are listed separately in Appendix. 

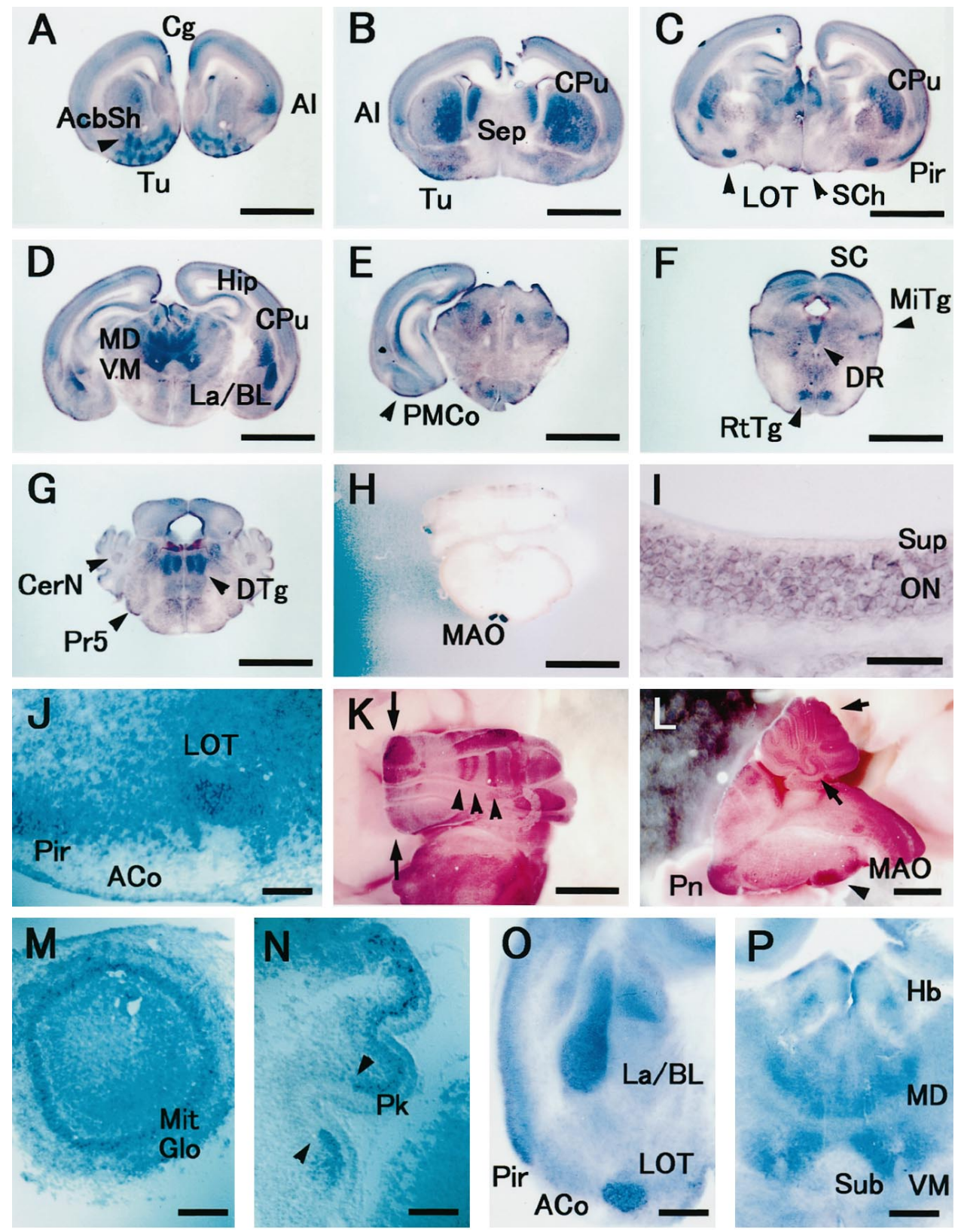

Figure 9. Expression of OL-pc mRNA in the postnatal brain and the OE. $A-H$, Coronal slices of the brain in order from rostral to caudal. I, OE. Note that only the deeplayer ON express OL-pc mRNA, whereas support cells (Sup) at the very surface of the epithelium do not express OL-pc mRNA. $J$, Higher magnification of the region of the LOT. $K$, Dorsal view of P5 Cer with wholemount staining. The prominent stripes are indicated by arrowheads. The Cer was cut along the midline (arrows). L, Lateral view of P5 rhombencephalon. The pontine nuclei $(P n)$ and MAO region of the inferior olive are stained, along with other nuclei. Arrows indicate the positive area in the cerebellar cortex. $M$, High magnification of cross section of MOB at P2. $N$, Coronal section of $\mathrm{Cer}$ at $\mathrm{P} 2$. Note that only the $\mathrm{Pk}$ is stained in some areas. Arrowheads indicate the boundaries of positive and negative area of the Pk. $O, P$, Higher magnification of amygdala region and thalamus, respectively. Abbreviations are listed in Appendix. Scale bars: $A-H, 2 \mathrm{~mm} ; I, 50 \mu \mathrm{m} ; J, M, N, 200 \mu \mathrm{m}$; $K, L, 1 \mathrm{~mm} ; O, P, 400 \mu \mathrm{m}$.

\section{Localization of OL-pc protein}

We also examined the localization of the OL-pc protein in various tissues. Using Western blot analysis with mAb 2G8 against the extracellular domain of OL-pc, we detected a $140 \mathrm{kDa}$ band and three minor bands of $\sim 100 \mathrm{kDa}$ in E15, P2, and adult mouse brain lysates (Fig. $3 B$ ). The mAb $2 \mathrm{H} 8$ raised against the cytoplasmic region of OL-pc showed similar results, except that the relative strength of the signal in the adult brain was much weaker than that seen with $\mathrm{mAb} 2 \mathrm{G} 8$, indicating that most of the OL-pc in the adult brain does not have the epitope recognized by $\mathrm{mAb} 2 \mathrm{H} 8$ at the cytoplasmic region.

We then examined whether the distribution of mRNA paralleled the protein distribution. The staining was generally weak, with high background in tissue sections. However, the observations could be categorized into three patterns. (1) The protein localization pattern was the same as that of the in situ hybridization. In those areas, the OL-pc-expressing cells usually existed as groups or clusters. For example, OL-pc protein was detected in a stripe pattern in E15 and E18 Cer (Figs. 8, 11, compare $A, D$ and $A, B$, respectively). These are precursors of Purkinje cells (Fig. $11 C-G)$. Similarly, OL-pc protein existed in the P2 MD, Hb, VM (Fig. $11 \mathrm{H}$ ), and parts of the amygdala, including the $\mathrm{La}$ and $\mathrm{BL}$ amygdaloid nuclei, where OL-pc was localized in the vicinity of the cell body. (2) The OL-pc protein was localized at the terminal regions of neurites. In the olfactory bulb at P2, glomeruli were stained strongly, whereas the staining in other regions appeared to be weaker (Fig. 11I). Higher magnification showed that small dot-like signals seemed to be deposited in the extracellular space at the glomerulus (Fig. 11J). In addition, the OL-pc protein was localized around the soma of Purkinje cells and in the molecular layer at P5 and P8, at which stage climbing fibers make synapses (Fig. $11 D-G$ ). The OL-pc protein seemed to be localized on the cell surface and maybe in the cytoplasm (Fig. 11F,G). The inferior olive, which is the source of the climbing fibers, also 

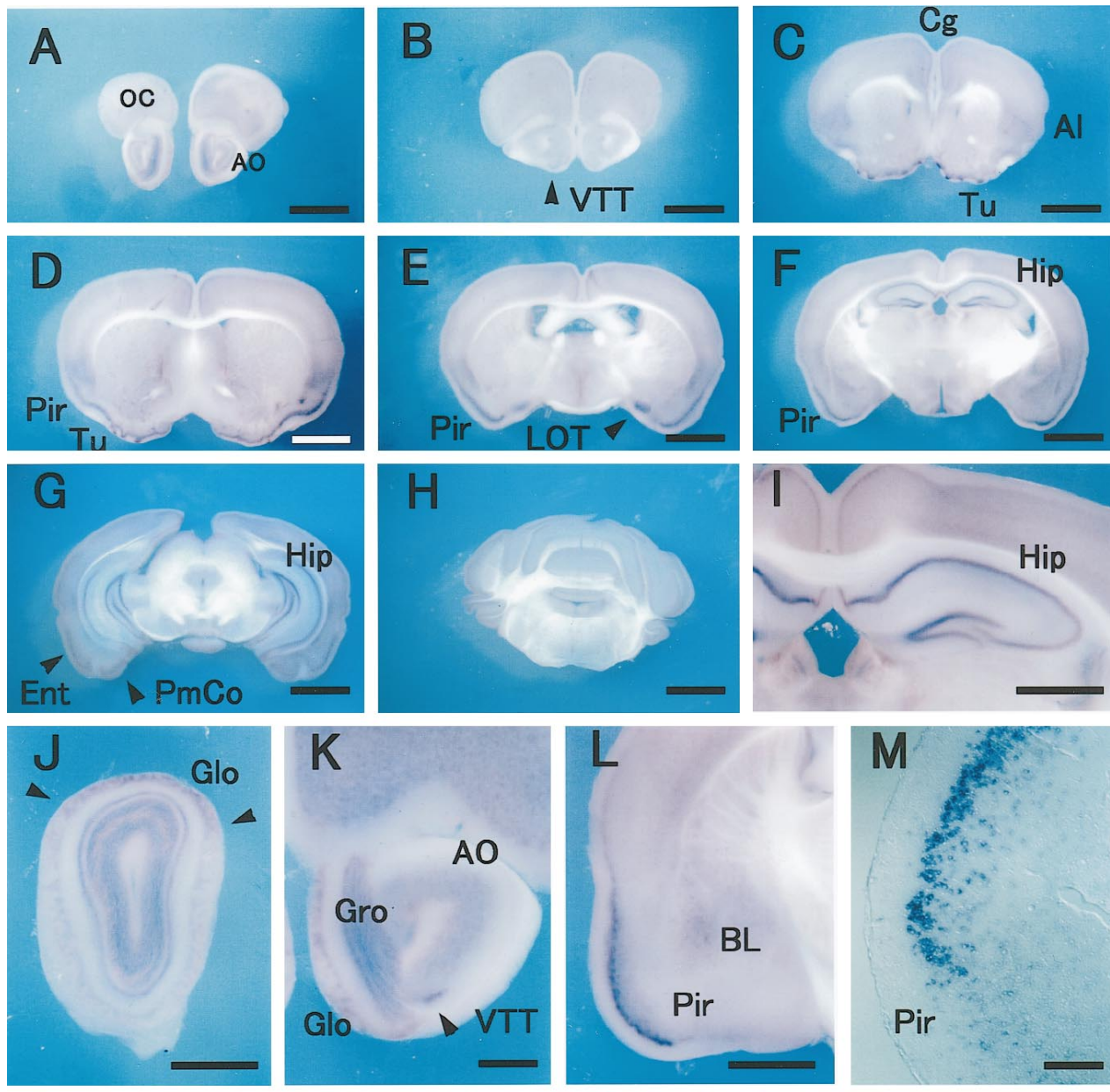

adult brain and retina $A-H$-p A mRNA in coronal slices of 8 -week-old brain. $I-L$, Higher magnification of the slices at the Hip, MOB, accessory olfactory bulb, and amygdala region, respectively. Note that the dorsal part of the Glo shows a stronger signal than the other layers $(J) . M-P$, Higher magnification of sections of the Pir, $\mathrm{Tu}, \mathrm{MOB}$, and retina, respectively. Note the large stained nuclei in the Pir and $\mathrm{Tu}$. Abbreviations are listed in Appendix. Scale bars: $A-H, 2 \mathrm{~mm} ; I, J, L, 1 \mathrm{~mm} ; K, 500 \mu \mathrm{m}$; $M-O, 200 \mu \mathrm{m} ; P, 100 \mu \mathrm{m}$.
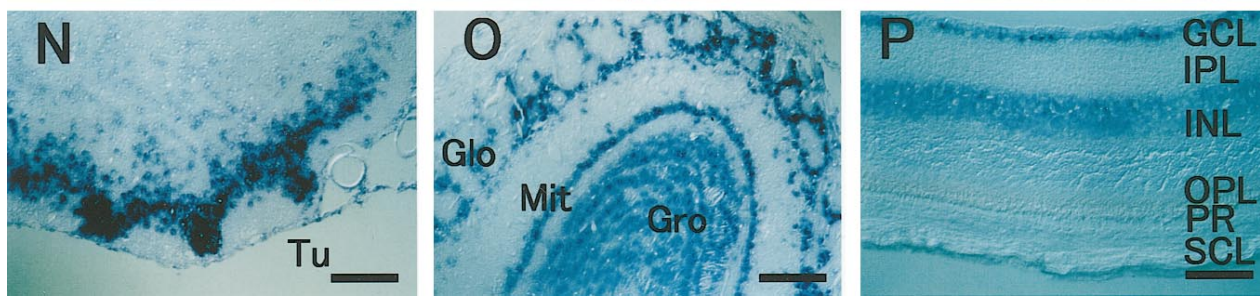

expressed OL-pc protein (data not shown). (3) No significant amount of the OL-pc protein could be detected at some regions of the P2 brain where the mRNA was expressed. These regions included the Pir, Tu, LOT, and Hip (data not shown). Because of the high background, we could not determine whether a small amount of OL-pc protein existed in these areas. We then examined the distribution of OL-pc in the target regions of these protein-negative structures to investigate the possibility that the protein was transported to the synaptic terminal. In the connections of the main olfactory system, the protein could be detected in some regions, such as the MD (the targets of Tu and Pir), and weakly in the granular layer of MOB (target of primary olfactory cortices), although they themselves expressed the mRNA. Other regions, such as the AI (a target of Pir and MD), Tu, and Pir (Tu and Pir are connected reciprocally), did not show significant staining (data not shown). Similarly, among the targets of the Hip, the BL and shell area of the accumbens nucleus (AcbSh) expressed both the mRNA and protein, whereas other targets, including the lateral septal nucleus (LS), anterior thalamic nuclei, and ventromedial hypothalamic nucleus, did not show significant staining of the protein. At this moment, it is difficult to know whether the OL-pc protein is transported from those unstained regions or not. Because of the high background, we could determine neither the OL-pc-positive regions in the adult brain nor subcellular localization in cells in primary culture.

\section{DISCUSSION}

\section{Molecular cloning and basic characteristics of OL-pc}

In the present report, we have described a novel protocadherin in the mouse brain. OL-pc seems to belong to a new group of the protocadherin family, because its cytoplasmic domain is wholly different from those of other protocadherins. One unique characteristic of OL-pc is that its EC2 region has the insertion of a glycine-rich sequence. This insertion does not seem to be an intron of abortive splicing, because we could find no splicing consensus sequences in this region of the cDNA.

The basic characteristics of OL-pc in the transfectants, such as weak adhesiveness, subcellular localization, binding specificities, and trypsin sensitivity, were similar to those of other protocadherins so far identified, such as pc2 and pc3 (Sano et al., 1993; 

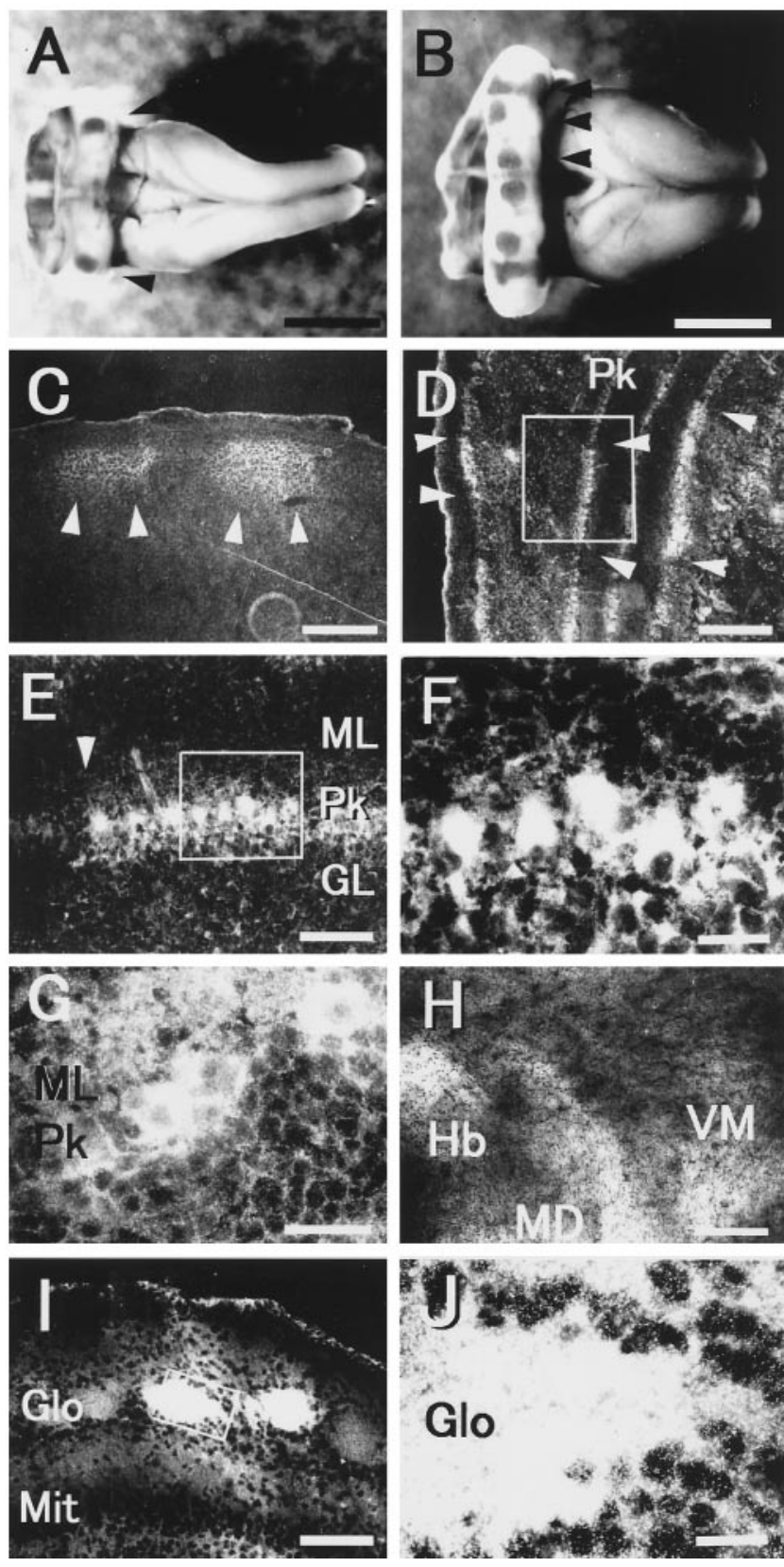

Figure 11. Distribution of OL-pc protein. $A, B$, Whole-mount staining of E15 $(A)$ and E18 $(B)$ Cer with mAb 2 H7. The signal was visualized by horseradish peroxidase and diaminobenzidine. The pattern is exactly the same as that obtained by in situ hybridization (compare with Fig. 8A,D). $C-J$, Indirect immunofluorescence microscopy of OL-pc. $C$, Staining of coronal section of E18 Cer with mAb 2H7. Patchy regions inside of E18 Cer show signal (arrowheads). D-F, Horizontal section of P5 Cer. Arrowheads indicates boundaries of positive and negative regions in the Pk. $E$ is a higher magnification of the boxed region in $D . F$ is a higher magnification of the boxed region in $E$. $G$, Higher magnification of Purkinje cells in P8 Cer. Signals in the ML have become prominent. $H$, The OL-pcpositive regions of the thalamic area. The coronal section is similar to the region shown in Figure 9D. Left is dorsal. I, J, A coronal section of the MOB. $J$ is the higher magnification of the boxed region in $I$. OL-pc has accumulated at glomeruli. Abbreviations are listed in Appendix. Scale bars: $A, B, 1 \mathrm{~mm} ; C, D, 200 \mu \mathrm{m} ; E, 50 \mu \mathrm{m} ; F, G, J, 20 \mathrm{~mm} ; H, I, 100 \mu \mathrm{m}$.
Sago et al., 1995). However, we do not know whether these characteristics can be applied to the native protocadherins in vivo, because expression in $\mathrm{L}$ cells is an artificial system in which OL-pc is not normally expressed. Here, we should point out that classical cadherins require catenins for their strong adhesion (Hirano et al., 1992). If protocadherins may need some cytoplasmic components that are lacking in L cells, the adhesion of protocadherins could be stronger in vivo than in the L cell system. The recent study by Bradley et al. (1998) clearly showed that NFprotocadherin mediates the adhesion of epidermis in vivo.

The interaction of the OL-pc molecule is homophilic in manner. The specificity appeared to be strict, because OL-pc did not interact with human pc2, rat pc3, and classical cadherins, although the amino acid sequences of their extracellular domains are similar. This specificity may be important for the recognition of the partners. Because many classical cadherins and protocadherins are expressed in overlapping regions in the CNS (see, for example, Suzuki et al., 1997; Obata et al., 1998), a combination of cadherins could give cells complex codes of adhesiveness and/or recognition ability. Such codes might enable formation of the complex neuronal networks in the nervous system (Redies, 1995; Redies and Takeichi, 1996).

Western blot analysis showed that the molecular mass of OL-pc in tissue was different from that of transfectants. We detected a $140 \mathrm{kDa}$ band in tissue and a $115 \mathrm{kDa}$ band in the transfectants. Because L and Neuro2A cells do not express endogenous OL-pc, it is very likely that modification is not properly accomplished in these cell lines.

\section{Expression of OL-pc}

The expression of OL-pc is restricted to some regions of the brain during development, suggesting at least two possible functions. It may be that OL-pc is involved in segregation of cell groups, such as brain nuclei, compartments, and cell layers. This notion was proposed and proved, at least in part, in the case of classical cadherins (Redies et al., 1993; Matsunami and Takeichi, 1995; Redies, 1995; Redies and Takeichi, 1996; Suzuki et al., 1997; Korematsu and Redies, 1997; Arndt et al., 1998). Although the strength of the adhesion by OL-pc was weak in transfectants, OL-pc may mediate strong adhesion in vivo or it may be principally involved in recognition and signal transduction rather than in simple mechanical connection.

Another possible function of OL-pc is the formation of the neural circuit. This view was originally proposed by the observation that expression of classical cadherins is associated with the functional system (Redies et al., 1993; Matsunami and Takeichi, 1995; Redies, 1995, 1997; Arndt and Redies, 1996; Redies and Takeichi, 1996). Similar to the expression of classical cadherins, the expression of OL-pc seems to be associated with a particular functional system. The best example is the main olfactory system, which includes MOB, TT, Tu, Pir, LOT, and Ent. Some parts of the limbic system, such as the Hip, amygdala, Hb, and DR, also express OL-pc, and the limbic system is related to the olfactory system. In particular, it is known that there is a strong connection between the prefrontal cortex, the MD, and the BLA, all of which express OL-pc (Price, 1994). However, the AON and ACo did not express OL-pc. Thus, OL-pc is expressed in a subset of the main olfactory system and the limbic system, although its expression is not perfect.

Another example of the correlation between OL-pc expression and functional systems is the MAO, which projects to the cerebellar nuclei and the cerebellar cortex. Similarly, the SCh and SC 
receive direct input from the retina, where the $\mathrm{SCh}$ and the ganglion cell expressed OL-pc. This correlation of OL-pc expression and its projection pattern must be important if OL-pc mediates target recognition or maintenance of the neural circuit.

The possible roles of OL-pc in the segregation of brain nucleicompartment and neural circuit formation may be comparable to those of classical cadherins, although the expression patterns of the two are different. However, the actions of these two adhesion molecules in such functions must be different, because their distinct cytoplasmic domains should have different signal transduction cascades. Future studies will be needed to reveal the different actions of protocadherins and classical cadherins in the formation of the CNS.

\section{Localization and distribution of OL-pc protein}

To examine the above hypothesis of OL-pc roles in the nervous system, we produced $\mathrm{mAbs}$ that recognized the $\mathrm{C}$-terminal region of OL-pc and tried to determine the tissue distribution of the protein. Unfortunately, these mAbs could be used only for the tissues fixed with $-20^{\circ} \mathrm{C}$ acetone, because paraformaldehyde fixation reduced the signal. Hence, the quality of tissue sections was too poor to examine details. Moreover, tissue sections produced high background in this condition, and then it was often difficult to determine the distribution. With these limitations, we examined OL-pc protein distribution in embryonic and postnatal tissue.

Two localization patterns of OL-pc protein are consistent with the proposed roles of OL-pc, which are based on the expression pattern of mRNA. First, the mAbs stained regions, such as the embryonic Cer, amygdala, and thalamic nuclei, in the same pattern as found in the in situ hybridization study, suggesting that OL-pc protein was localized in the vicinity of the cell body. Because OL-pc protein was accumulated at the cell-cell junction in transfectants, OL-pc may be involved in the segregation of nuclei or compartments in those regions. However, we cannot rule out the possibility that OL-pc may be involved in formation of inhibitory synapses, which are generally present on the cell body surfaces.

Second, OL-pc protein was accumulated at the glomeruli, which are rich in synapses, in the olfactory bulb at P2. Another intriguing localization of OL-pc protein is at the vicinity of postnatal Purkinje cells. It is known that the climbing fibers make synapses around Purkinje cells at this stage (Altman and Bayer, 1996). Because the inferior olive, the major source of climbing fibers, also expressed OL-pc, OL-pc could mediate the synaptic interaction of Purkinje cells and climbing fibers. These observations lead to the speculation that OL-pc may localize at the synapse to form the neural circuit. It should be remembered that $\mathrm{N}$-cadherin and $\mathrm{Cnr}$ are localized at the synapse (Yamagata et al., 1995; Fannon and Colman, 1996; Uchida et al., 1996, Kohmura et al., 1998).

By the combination of these two actions, OL-pc may contribute to the formation of a precise neural network, as highlighted in the Cer. In the embryonic stage, OL-pc seems to mediate cell-cell adhesion to form compartments of the same kind of cells (Fig. $11 A-C)$. In the postnatal stage, OL-pc may be responsible for target recognition at the synapse (Fig. $11 D-G)$. In the adult stage, expression of OL-pc is faint (Fig. 10H), suggesting that it may no longer be needed to maintain neural connections.

We could not detect significant signals with the mAbs in the Hip, Tu, LOT, and Pir, where OL-pc mRNA is expressed at high levels. There are three possible explanations for these results.
First, high background of immunostaining may hinder us from detecting weak signal. Second, OL-pc protein may be transported to synaptic terminals located quite far from the cell body. Considering the example of the glomerulus of MOB, where the OL-pc protein is accumulated, this explanation could be possible. However, at this moment, we cannot conclude whether detected protein in their target regions is transported or not, because target regions themselves often express OL-pc mRNA. The third possibility is that other forms of OL-pc are expressed in these regions. In the Western blot analysis, there was quite a difference in the amount between 2G8 and 2H8 blots in the adult Hip (Fig. $3 B$ ). This suggests that in the adult Hip, the C-terminal of OL-pc is different from that in the embryonic Hip. In fact, we recently cloned another type of OL-pc cDNA that encoded a different C-terminal sequence in the adult brain (Hirano and Suzuki, unpublished observations).

The present study is the first step to elucidate the role of OL-pc in the formation of the nervous system.

\section{APPENDIX}

Anatomical abbreviations used in text, figures, and/or table are as follows: AcbSh, accumbens nucleus, shell; ACo, anterior cortical amygdaloid nucleus; AI, agranular insular cortex; AON, anterior olfactory nucleus; BL, basolateral amygdaloid nucleus; BLA, basolateral amygdaloid nucleus, anterior part; Cer, cerebellum; CerN, cerebellar nucleus; $\mathrm{Cg}$, cingulate cortex; $\mathrm{CPu}$, caudate putamen; DR, dorsal raphe nucleus; DTg, dorsal tegmental nucleus; Ent, entorhinal cortex; Epi, epithalamus; GCL, ganglion cell layer; GL, granular layer of the cerebellum; Glo, glomerular layer of the olfactory bulb; GP, globus pallidus; Gro, granule layer of the olfactory bulb; Hb, habenular nucleus; Hip, hippocampus; INL, inner nuclear layer; IPL, inner plexiform layer; La, lateral amygdaloid nucleus; LOT, nucleus of the lateral olfactory tract; LS, lateral septal nucleus; MAO, medial accessory olive; Mit, mitral cell layer of the olfactory bulb; MiTg, microcellular tegmental nucleus; ML, molecular layer of the cerebellum; MOB, main olfactory bulb; MD, mediodorsal thalamic nucleus; OC, orbitofrontal cortex; OE, olfactory epithelium; ON, olfactory sensory neurons; OPL, outer plexiform layer; Pir, piriform cortex; $\mathrm{Pk}$, Purkinje cell layer; PLCo, posterolateral cortical amygdaloid nucleus; PMCo, posteromedial cortical amygdaloid nucleus; Pn, pontine nuclei; PR, pigmented retina; Pr5, principal sensory trigeminal nucleus; RtTg, reticulotegmental nucleus of the pons; SC, superior colliculus; SCh, suprachiasmatic nucleus; SCL, sclera; Sep, lateral septum; Sub, submedius thalamic nucleus; Sup, support cells of olfactory epithelium; TT, tenia tecta; Tu, olfactory tubercle; VM, ventromedial thalamic nucleus; VOE, vomeronasal epithelium; VTT, ventral tenia tecta.

\section{REFERENCES}

Altman J, Bayer SA (1996) Development of the cerebellar system. Boca Raton, FL: CRC.

Arndt K, Redies C (1996) Restricted expression of R-cadherin by brain nuclei and neural circuits of the developing chicken brain. J Comp Neurol 373:373-399.

Arndt K, Nakagawa S, Takeichi M, Redies C (1998) Cadherin-defined segments and parasagittal cell ribbons in the developing chicken cerebellum. Mol Cell Neurosci 10:211-228.

Bradley RS, Espeseth A, Kintner C (1998) NF-protocadherin, a novel member of the cadherin superfamily, is required for Xenopus ectodermal differentiation. Curr Biol 8:325-334.

Fannon AM, Colman DR (1996) A model for central synaptic junctional complex formation based on the differential adhesive specificities of the cadherins. Neuron 17:423-434. 
Franklin KBJ, Paxinos G (1997) The mouse brain in stereotaxic coordinates. San Diego: Academic.

Fujimori T, Miyatani S, Takeichi M (1990) Ectopic expression of $\mathrm{N}$-cadherin perturbs histogenesis in Xenopus embryos. Development 110:97-104.

Hirano S, Nose A, Hatta K, Kawakami A, Takeichi M (1987) Calciumdependent cell-cell adhesion molecules (cadherins): subclass specificities and possible involvement of actin bundles. J Cell Biol 105:2501-2510.

Hirano S, Kimoto N, Shimoyama Y, Hirohashi S, Takeichi M (1992) Identification of a neural alpha-catenin as a key regulator of cadherin function and multicellular organization. Cell 70:293-301.

Huynh TV, Young RA, Davis RW (1985) Construction and screening cDNA libraries in $\lambda \mathrm{gt} 10$ and $\lambda \mathrm{gt} 11$. In: DNA cloning: a practical approach, Vol I (Glover DM, ed), pp 49-78. Oxford: IRL.

Kohler G, Milstein C (1975) Continuous cultures of fused cells secreting antibody of predefined specificity. Nature 256:495-497.

Kohmura N, Senzaki K, Hamada S, Kai N, Yasuda R, Watanabe M, Ishii H, Yasuda M, Mishina M, Yagi T (1998) Diversity revealed by a novel family of cadherins expressed in neurons at a synaptic complex. Neuron 20:1137-1151.

Korematsu K, Redies C (1997) Expression of cadherin-8 mRNA in the developing mouse central nervous system. J Comp Neurol 387:291-306.

Kozak M (1984) Compilation and analysis of sequences upstream from the translational start site in eukaryotic mRNAs. Nucleic Acids Res 12:857-872.

Matsunami H, Takeichi M (1995) Fetal brain subdivisions defined by Rand E-cadherin expressions: evidence for the role of cadherin activity in region-specific, cell-cell adhesion. Dev Biol 172:466-478.

Matsuyoshi N, Imamura S (1997) Multiple cadherins are expressed in human fibroblasts. Biochem Biophys Res Commun 235:355-358.

Miyatani S, Shimamura K, Hatta M, Nagafuchi A, Nose A, Matsunaga M, Hatta K, Takeichi M (1989) Neural cadherin: role in selective cell-cell adhesion. Science 245:631-635.

Nagafuchi A, Takeichi M (1988) Cell binding function of E-cadherin is regulated by the cytoplasmic domain. EMBO J 7:3679-3684.

Obata S, Sago H, Davidson M, St. John T, Suzuki ST (1998) Multiple protocadherins share the same sequence in their cytoplasmic domains and are expressed in different regions of brains. Cell Adhes Commun 6:323-333.

Paxinos G (1994) The rat nervous system, Ed 2 (Paxinos G, ed). San Diego: Academic.

Price JL (1994) Thalamus. In: The rat nervous system, Ed 2 (Paxinos G, ed), pp 629-648. San Diego: Academic.

Redies C (1995) Cadherin expression in the developing vertebrate brain: from neuromeres to brain nuclei and neural circuits. Exp Cell Res 220:243-256.

Redies C (1997) Cadherins and the formation of neural circuitry in the vertebrate CNS. Cell Tissue Res 290:405-413.

Redies C, Takeichi M (1996) Cadherins in the developing central nervous system: an adhesive code for segmental and functional subdivisions. Dev Biol 180:413-423.

Redies C, Engelhart K, Takeichi M (1993) Differential expression of Nand R-cadherin in functional neuronal systems and other structures of the developing chicken brain. J Comp Neurol 333:398-416.
Ressler KJ, Sullivan SL, Buck LB (1993) A zonal organization of odorant receptor gene expression in the olfactory epithelium. Cell 73:597-609.

Sago H, Kitagawa M, Obata S, Mori N, Taketani S, Rochelle JM, Seldin M, Davidson M, St. John T, Suzuki ST (1995) Cloning, expression, and chromosomal localization of a novel cadherin-related protein, protocadherin-3. Genomics 29:631-640.

Sambrook J, Fritsch EF, Maniatis T (1989) Molecular cloning: a laboratory manual. Cold Spring Harbor, NY: Cold Spring Harbor Laboratory.

Sano K, Tanihara H, Heimark RL, Obata S, Davidson M, St. John T, Taketani S, Suzuki S (1993) Protocadherins: a large family of cadherin-related molecules in central nervous system. EMBO J 12:2249-2256.

Schambra UB, Lauder JM, Silver J (1992) Atlas of the prenatal mouse brain (Schambra UB, Lauder JM, Silver J, eds). San Diego: Academic.

Shipley MT, McLean JH, Ennis M (1994) Olfactory system. In: The rat nervous system, Ed 2 (Paxinos G, ed), pp 899-926. San Diego: Academic.

Suzuki SC, Inoue T, Kimura Y, Tanaka T, Takeichi M (1997) Neuronal circuits are subdivided by differential expression of type-II classic cadherins in postnatal mouse brains. Mol Cell Neurosci 9:433-447.

Suzuki ST (1996a) Protocadherins and diversity of the cadherin superfamily. J Cell Sci 109:2609-2611.

Suzuki ST (1996b) Structural and functional diversity of cadherin superfamily: are new members of cadherin superfamily involved in signal transduction pathway? J Cell Biochem 61:531-542.

Takeichi M (1977) Functional correlation between cell adhesive properties and some cell surface proteins. J Cell Biol 75:464-474.

Takeichi M (1988) The cadherins: cell-cell adhesion molecules controlling animal morphogenesis. Development 102:639-655.

Takeichi M (1991) Cadherin cell adhesion receptors as a morphogenetic regulator. Science 251:1451-1455.

Takeichi M (1995) Morphogenetic roles of classic cadherins. Curr Opin Cell Biol 7:619-627.

Uchida N, Honjo Y, Johnson KJ, Wheelock MJ, Takeichi M (1996) The catenin/cadherin adhesion system is localized in synaptic junctions bordering transmitter release zones. J Cell Biol 135:767-779.

Voogd J (1994) Cerebellum. In: The rat nervous system, Ed 2 (Paxinos G, ed), pp 309-350. San Diego: Academic.

Yamagata M, Herman JP, Sanes JR (1995) Lamina-specific expression of adhesion molecules in developing chick optic tectum. J Neurosci 15:4556-4571.

Yamamoto A, Amacher SL, Kim S-H, Geissert D, Kimmel CB, De Robertis EM (1998) Zebrafish paraxial protocadherin is a downstream target of spadetail involved in morphogenesis of gastrula mesoderm. Development 125:3389-3397.

Yoshida K, Yoshomo-Nakagawa K, Seki N, Sasaki M, Sugano S (1998) Cloning, expression analysis, and chromosomal localization of $\mathrm{BH}-$ protocadherin, a novel member of the cadherin superfamily. Genomics 49:458-461.

Wilkinson DG (1992) Whole mount in situ hybridization of vertebrate embryos. In: In situ hybridization: a practical approach (Wilkinson DG, ed), pp 75-83. Oxford: IRL. 